Eur. J. Clin. Chem. Clin. Biochem.

Vol. 32, 1994, pp. 589-593

(c) 1994 Walter de Gruyter \& Co. Berlin - New York

\title{
Immunoreactive Creatine Kinase-MB and Creatine Kinase Isozyme Concentrations During Treatment of Hypothyroid Patients
}

\author{
By Takako Miyamoto ${ }^{1}$, Akio Nagasaka ${ }^{1}$,Kanefisa Kato ${ }^{2}$, Rumi Masunaga ${ }^{1}$, Motoko Kotake ${ }^{1}$, Tetsuya Kawabe ${ }^{1}$, \\ Akira Nakai ', Takehiko Mokuno ${ }^{1}$, Yoshikuni Sawai ', Naohisa Oda ${ }^{1}$, Toshiki Mano ${ }^{1}$ and Yuko Nishida ${ }^{1}$ \\ 1 Department of Internal Medicine, Fujita Health University School of Medicine, Toyoake, Aichi 470-11 \\ 2 Institute for Developmental Research, Aichi Prefecture Colony, Kasugai, Aichi 480-03, Japan
}

(Received July 20, 1993/January 17/April 27, 1994)

\begin{abstract}
Summary: Using a highly sensitive enzyme immunoassay (EIA) system, we determined creatine kinase isozymes, namely creatine kinase-MB and creatine kinase-MM, in sera of patients suffering from primary hypothyroidism with concomitant signs of myocardial affections before and during treatment. After oral administration of $L$-thyroxine, the augmented mass concentrations of serum creatine kinase-MB and creatine kinase-MM, and the increased catalytic activity concentrations of serum total creatine kinase and creatine kinase-MB gradually decreased in inverse proportion to the increased concentrations of serum triiodothyronine $\left(\mathrm{T}_{3}\right)$ and thyroxine $\left(\mathrm{T}_{4}\right)$. By the 6th to 8th week after treatment, the elevated levels of serum total creatine kinase and creatine kinase-MB catalytic activity concentrations (assayed by a routine method) and serum creatine kinase-MM mass concentrations (assayed by EIA) declined to normal values, while serum $\mathrm{T}_{3}, \mathrm{~T}_{4}$, and thyroid stimulating hormone attained normal values. Serum creatine kinase-MB mass concentrations (assayed by EIA), however, still remained at the higher level, without complete recovery from myocardial damage, as shown by electrocardiogram (ECG).
\end{abstract}

These data indicate that metabolic distortion still exists in the myocardium, as revealed by the high creatine kinaseMB mass concentration, especially as assayed by EIA, even though the plasma levels of thyroid hormones had returned to normal.

\section{Introduction}

Creatine kinase plays an important role in energy metabolism in muscles. Three isozymes are recognized, and these exhibit tissue-specificity in their mode of distribution; the $\mathrm{BB}$ form is found in the brain, the $\mathrm{MB}$ form in the heart, and the MM form in the skeletal muscles (1, 2). Isozyme, creatine kinase-MB, is easily released from cardiac muscle after acute myocardial infarction (3-5). Hypothyroidism induces the elevation of serum creatine kinase, aspartate aminotransferase and lactate dehydrogenase activity concentrations, accompanied by electrocardiographic changes and signs of distorted skeletal muscle metabolism $(6,7)$ : Gradual recovery from these changes occurs after thyroid hormone replacement therapy (8). In this study, we determined the serum mass concentration of creatine kinase-MB and creatine kinase-MM during treatment of hypothyroidism, using a highly sensitive enzyme immunoassay system which was able to detect lower serum levels of creatine kinaseMB $(9,10)$; this confirmed that serum creatine kinaseMB levels still remained high, even though serum concentrations of thyroid stimulating hormone and thyroid hormones, and the serum catalytic activity concentrations of total creatine kinase and creatine kinase-MB measured by the routine method were normalized.

\section{Materials and Methods}

The subjects for this study were 20 patients (aged from 45 to 67 years) at our university hospital, with relativcly scvere hypothyroidism due to chronic thyroiditis (12 cases) and idiopathic hypo- 
thyroidism (8 cases) associated with abnormal elevation of creatine kinase isozyme catalytic activity concentrations. These patients revealed high serum catalytic activity concentration of total creatine kinase and high serum mass concentration of creatine kinase-MB. In all these patients, abnormal ECG findings (bradycardia and ST changes) were noted, suggesting myocardial damage due to hypothyroidism, as shown by cardiac muscle biopsy (11). None of the patients showed evidence of other cardiac diseases. Serum samples were collected every 2 weeks for 8 weeks after the administration of $L$-thyroxine (up $50 \mu \mathrm{g} /$ day every 1.5 weeks). We were able to check ECGs in 18 of these 20 patients during the course of the treatment. Blood samples were taken from a cubital vein in the early morning after fasting, then centrifuged to obtain the sera, which were stored at $-40^{\circ} \mathrm{C}$ until use.

For the determination of creatine kinase isozyme mass concentration, we used a highly sensitive enzyme immunoassay (EIA), developed by Kato et al. (9), which has the capacity to detect a lower concentration of creatine kinase isozymes than the minimal concentration detectable by a routine method. A routine method for the determination of creatine kinase-MB catalytic activity concentration was reported previously (12). The principle of this method is the direct measurement of creatine kinase-B subunit at $37^{\circ} \mathrm{C}$ by inhibiting $M$ subunits with $M$ subunit antibody. A method for total creatine kinase was reported by Szász et al. (13). Total creatine kinase catalytic activity concentration was measured at $37^{\circ} \mathrm{C}$, using the Technicon RA system (Technicon Instruments Corporation, New York, USA). Creatine kinase-MB catalytic activity concentration is within $9 \%$ of total creatine kinase activity. The normal ranges reported in these papers were confirmed in our laboratory, using 50-60 samples from healthy subjects.

\section{Results}

Changes of serum creatine kinase-MB and creatine kinase-MM mass concentrations and total creatine kinase and creatine kinase-MB catalytic activity concentration were analysed during the treatment of hypothyroid patients.

The augmented mass concentrations of serum creatine kinase-MB and creatine kinase-MM assayed by EIA and the increased catalytic activity concentration of serum total creatine kinase and creatine kinase-MB assayed by a routine method decreased gradually in inverse proportion to the increase in serum triiodothyronine $\left(\mathrm{T}_{3}\right)$ and thyroxine $\left(\mathrm{T}_{4}\right)$ levels. By the 6 th -8 th week after treatment, serum catalytic activity concentrations of total creatine kinase and creatine kināse-MB assayed by a routine method, and serum mass concentrations of creatine kinase-MM assayed by EIA reached normal values (fig. 1), corresponding to the normalization of serum $T_{3}$, $\mathrm{T}_{4}$, and thyrotropin levels (tab. 1). However, at this point, serum mass concentrations of creatine kinase-MB assayed by EIA were very low compared with those of total creatine kinase; they were hard to detect by a rou-
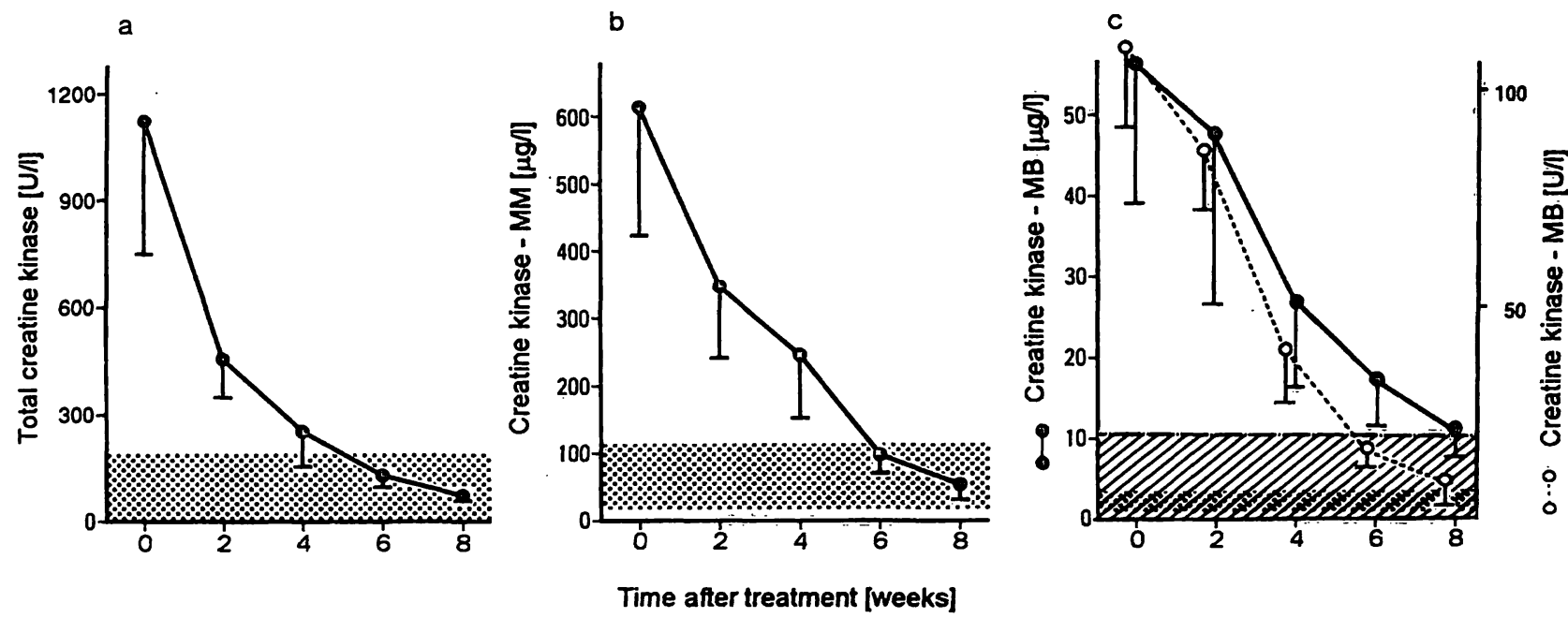

Fig. 1 Changes in serum levels of total creatine kinase (a) and creatine kinase isozymes (b) and (c) in hypothyroid patients during treatment. Values are the mean \pm SE of 15 patients.

Shaded areas 0 show the normal range in a highly sensitive enzyme immunoassay. In panel $\mathrm{c}$, the oblique line area $\mathbb{G}$ shows

the normal range of creatine kinase-MB assayed by a routine method.

- - creatine kinase-MB assayed by a highly sensitive enzyme immunoassay;

O---O: creatine kinase-MB assayed by a routine method. ..

Tab. 1 Serum concentrations of thyrotropin and thyroid hormones in 20 hypothyroid patients during the oral administration of $L$-thyroxine.

\begin{tabular}{lcccccc}
\hline Weeks after treatment & 0 & & 2 & 4 & 6 & 8 \\
\hline Thyrotropin $[\mathrm{mU} / 1](0.4-3.5)$ & $153 \pm 11$ & $65.6 \pm 5.2$ & $32.6 \pm 4.2$ & $11.2 \pm 3.2$ & $3.2 \pm 0.8$ \\
Triiodothyronine $[\mu \mathrm{g} / 1](54-105)$ & $19 \quad \pm 3$ & $38 \pm 7$ & $51 \pm 8$ & 81 & \pm 11 & 86 \\
Thyroxine $[\mu \mathrm{g} / \mathrm{l}](0.7-1.6)$ & $0.40 \pm 0.08$ & $0.63 \pm 0.10$ & $0.90 \pm 0.15$ & $0.97 \pm 0.14$ & $1.20 \pm 0.18$ \\
\hline
\end{tabular}

The values are the mean $\pm \mathrm{SE}$.

The values in parentheses present the normal range in 50 healthy persons measured in our laboratory. : 
Tab. 2 Changes in serum concentrations of thyroid hormones, thyrotropin and creatine kinase isozymes and changes of ECG during the treatment of hypothyroid patients (case 1 and 2).

Case 1.

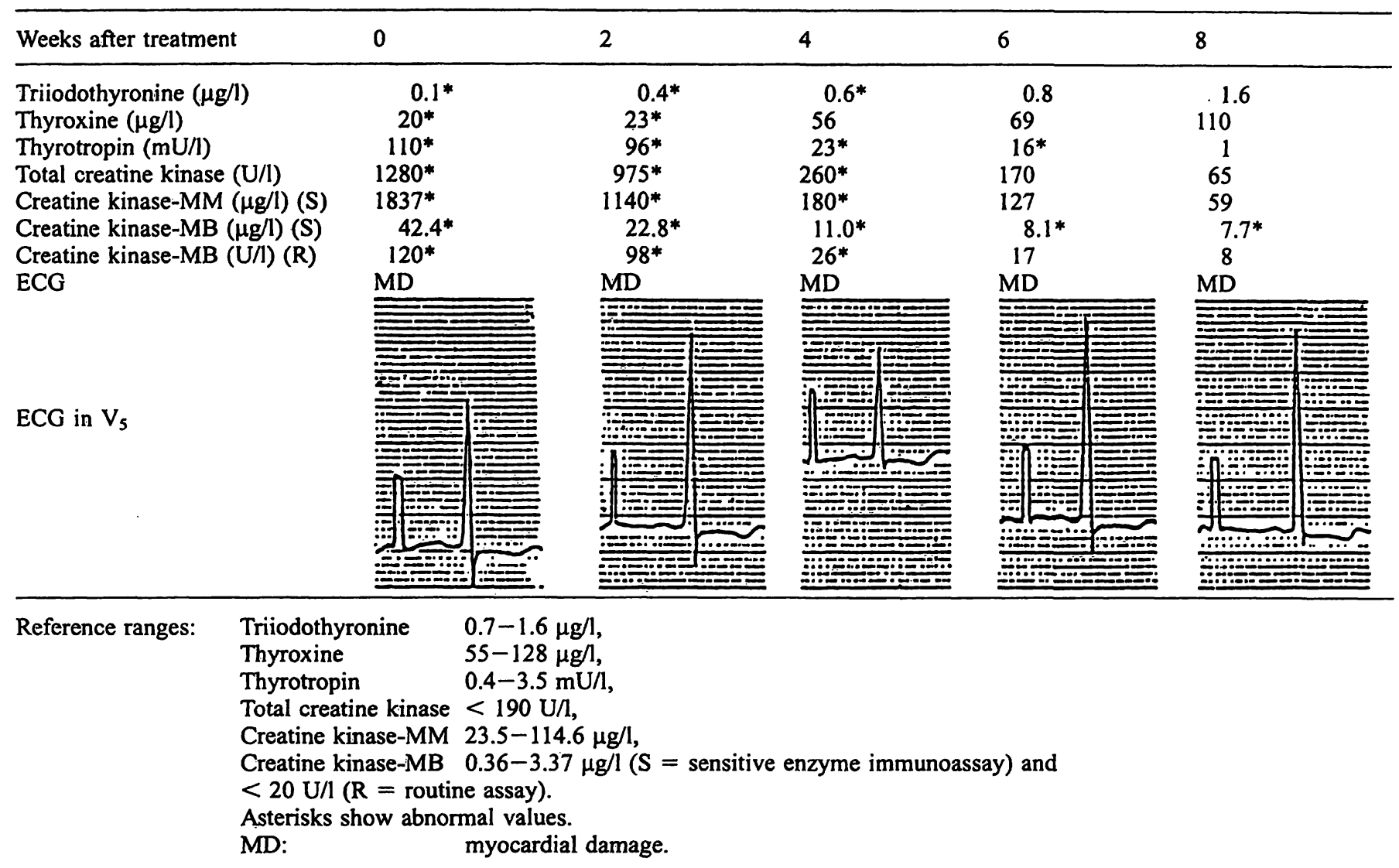

Cașe 2.

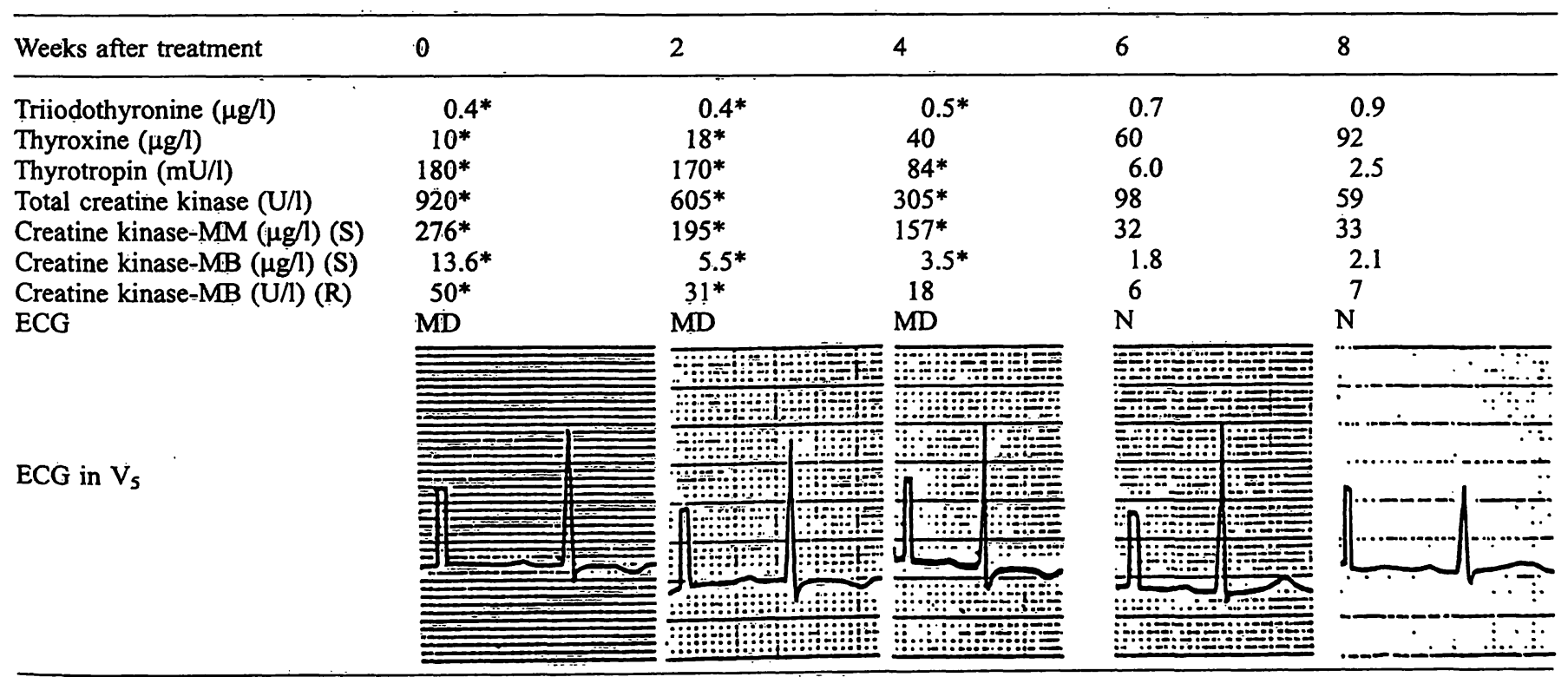

\begin{tabular}{|c|c|c|}
\hline Reference ranges: & $\begin{array}{l}\text { Triiodothyronine } \\
\text { Thyroxine } \\
\text { Thyrotropin } \\
\text { Total creatine kinase } \\
\text { Creatine kinase-MM } \\
\text { Creatine kinase-MB } \\
<20 \mathrm{U} / \mathrm{R}=\text { routin } \\
\text { Asterisks show abnor } \\
\text { MD: }\end{array}$ & $\begin{array}{l}0.7-1.6 \mu \mathrm{g} / \mathrm{l}, \\
55-128 \mu \mathrm{g} / \mathrm{l}, \\
0.4-3.5 \mathrm{mU} / \mathrm{l}, \\
<190 \mathrm{U} / \mathrm{l}, \\
23.5-114.6 \mu \mathrm{g} / \mathrm{l}, \\
0.36-3.37 \mu \mathrm{g} / \mathrm{l}(\mathrm{S}=\text { sensitive enzyme immunoassay) and } \\
\text { ne assay). } \\
\text { rmal values. } \\
\text { myocardial damage. }\end{array}$ \\
\hline
\end{tabular}


tine method, but could be measured by a highly sensitive method; they still remained high in 12 patients (fig. lc). In these latter 12 patients, the myocardial damage shown in the ECGs had not improved ( 7 cases of chronic thyroiditis, 5 cases of idiopathic hypothyroidism). The representative case is shown in table 2 (case 1 ). In the other six patients ( 3 cases of chronic thyroiditis, 3 cases of idiopathic hypothyroidism) who were checked by ECGs, the ST changes in ECGs subsided when the serum levels of creatine kinase-MB (assayed by EIA, not by a routine method) reached normal values during the course of the treatment (the representative case is shown in tab. 2, case 2). High creatine kinase-MB mass concentrations assayed by EIA declined to normal levels by the 12-14th week after treatment, concomitantly with normalization of the ECG (data not shown). The changes in serum catalytic concentrations of aspartate aminotransferase and lactate dehydrogenase in these patients paralleled changes in the catalytic activity concentration of total creatine kinase and the mass concentration of creatine kinase-MM.

\section{Discussion}

Since the distribution of creatine kinase isozymes is tissue-specific, several investigators $(1,2)$ have analysed serum levels and tissue contents of creatine kinase-isozymes, in order to estimate tissue damage in hypothyroid patients. It has been reported that in hypothyroidism, the isozyme analysis of elevated creatine kinase levels shows primarily an MM pattern, although a trace MB fraction could be seen, suggesting that the source of the creatine kinase elevations was skeletal muscle (14). Our study clarified the fact that changes in serum total creatine kinase and creatine kinase-MB catalytic activity concentration and serum creatine kinase-MM and creatine kinase-MB mass concentrations correlate reciprocally with serum levels of thyroid hormones. However, the serum level of creatine kinase-MB, measured by a highly sensitive method, were still high. This creatine kinase-MB may arise from heart muscle rather than skeletal muscle, because the serum mass concentration of creatine kinase-MM, which represented more than $90 \%$ of creatine kinase-isozymes, was normalized. The ECG changes persisted when serum levels of thyroid hormones had been normalized by thyroid hormone replacement therapy. The change in creatine kinase-MB mass concentrations may be mainly due to heart tissue, while the change in creatine kinase-MM mass concentrations is mainly due to leg muscle tissue. It can be speculated that since changes of creatine kinase $-\mathrm{MM}$ precede those of creatine kinase-MB, recovery proceeds more rapidly in skeletal muscle than in myocardium. In addition to acute myocarditis and cardiomyopathy (15), which cause reversible ECG changes and cardiac enzyme abnormalities in the absence of myocardial infarction, hypothyroid patients also frequently display reversible myocardial damage associated with elevated cardiac enzyme activities. In patients with hypothyroidism and irreversible ECG changes induced by irreversible chronic myocardial damage, the reversible cardiac enzyme abnormality, such as creatine kinase-MB, may be only a useful marker for hypothyroid-induced myocardial damage.

Latner et al. (16) have confirmed that creatine kinase$\mathrm{MB}$ isozyme concentrations in the serum of uraemic patients, measured by chemiluminometric immunoassay, correlated with those determined by an electrophoretic method. Eisenberg et al. (17) have also reported that the rates of decrease in creatine kinase-MB catalytic activity and mass concentration after attaining their peak values were comparable in plasma samples from patients with myocardial infarction. Therefore, there may be no difference in the decay of creatine kinase-MB catalytic activity and mass concentration, or in the different subspecies of creatine kinase-MB molecules, so that the data shown in figure lc cannot be interpreted on this basis.

When serum levels of creatine kinase-MB (measured by a highly sensitive method $(9,18)$ in hypothyroid patients treated with thyroid hormones) still remain high, even though serum levels of thyroid hormones, routinely measured total creatine kinase and creatine kinase-MB catalytic activity concentrations and EIA-assayed creatine kinase-MM mass concentrations have become normal, careful attention must be paid to the cardiovascular system of the patient.

\section{References}

1. Dawson, D. M., Eppenberger, H. M. \& Kaplan, N. O. (1965) Creatine kinase: Evidence for a dimeric structure. Biochem. Biophys. Res. Commun. 21, 346-353.

2. Chemnitz, G., Schmidt, E. \& Schmidt, F. W. (1981) Creatine kinase and isoenzymes in hypothyroidism. In: Creatine Kinase Isozymes (Lang, H., ed.) Springer Verlag, Berlin/Heidelberg/ New York, pp. 183-185.

3. Hadberg, A., Hassager, C., Hildebrandt, P. \& Christiansen, C. (1990) Comparison of two immunoinhibitory methods with

agarose gel-electrophoresis for measuring the MB isoenzyme of creatine kinase in serum from cases; of suspected myocardial infarction. J. Clin. Chem. Clin. Biochem. 28, 453-458.

4. Shioler, V., Thode, J. \& Kjoller, E. (1992) Performance characteristics of creatine kinase-MB isoenzyme measured with an immunoenzymometric and an immunoinhibition assay in acute myocardial infarction with and without thrombolytic therapy. Eur. J. Clin. Chem. Clin. Biochem. 30, 357-361. 
5. Delanghe, J. R., DeBuyzere, M. L., Cluyse, L. P., Thierens, H. M. \& Clement, D. L. (1992) Acute myocardial infarction size and myoglobin release into serum. Eur. J. Clin. Chem. Clin. Biochem. 30, 823-830.

6. Craig, F. A. \& Ross, G. (1963) Serum creatine phosphokinase in thyroid disease. Metabolism 12, 57-59.

7. Craig, F. A. \& Smith, J. C. (1965) Serum creatine phosphokinase activity in altered thyroid states. J. Clin. Endocrinol. 25, 723-731.

8. Klein, I., Mantell, P., Parker, M. \& Levery, G. (1980) Resolution of abnormal muscle enzyme studies in hypothyroidism. Am. J. Med. Sci. 279, 159-162.

9. Kato, K., Shimizu, A., Ishiguro, Y., Mokuno, K., Ariyoshi, Y. \& Nakajima, T. (1985) Highly sensitive enzyme immunoassay for human creatine kinase BB isozyme. Clin. Chim. Acta $150,31-40$.

10. Kato, K. \& Shimizu, A. (1986) Highly sensitive enzyme immunoassay for human creatine kinase $\mathrm{MM}$ and $\mathrm{MB}$ isozymes. Clin. Chim. Acta 158, 99-108.

11. Hayasaki, K., Sekiguchi, M. \& Hirosawa, K. (1978) Histopathology and ultrastructure of myocardium in five patients with myxedema employing endomyocardial biopsy. Heart (in Japanese) $10,1022-1028$.

12. Würzburg, U., Hennrich, N. \& Lang, H. (1976) Bestimmung der Aktivität von Creatinkinase $\mathrm{MB}$ in Serum unter Verwendung inhibierender Antikörper. Klin. Wochenschr. 54, 357360 .
13. Szasz, G., Gruber, W. \& Bernt, E. (1976) Creatine kinase in serum: Determination of optimum reaction conditions. Clin. Chem. 22, 650-656.

14. Goldman, J., Matz, R., Mortimer, R. \& Freeman, R. (1977) High elevations of creatine phosphokinase in hypothyroidism. An isoenzyme analysis. J. Am. Med. Ass. 238, 325-326.

15. Nagata, S., Park, Y-D., Minamikawa, T., Yutani, C., Kamiya T., Nishimura, T., Kozuka, T., Sakakibara, H. \& Nimura, Y. (1985) Thallium perfusion and cardiac enzyme abnormalities in patients with familial hypertrophic cardiomyopathy. Am. Heart J. 109, 1317-1322.

16. Latner, B. P., Skale, J. S. \& Burns, W. (1989) Measuring creatine kinase $M B$ isoenzyme in a maintenance hemodialysis population: Chemiluminometric immunoassay and electrophoresis compared. Clin. Chem. 35, 1965-1968.

17. Eisenberg, P. R., Shaw, D., Schaab, C. \& Jaffe, A. S. (1989) Concordance of creatine kinase-MB activity and mass. Clin. Chem. 35, 440-443.

18. Piran, U., Kohn, D. W., Uretsky, L. S., Barner, D., Barlow, E. H., Niswander, C. A. \& Stastny, M. (1987) Immunochemiluminometric assay of creatine kinase $\mathrm{MB}$ with a monoclonal antibody to the MB isoenzyme. Clin. Chem. 33, 1517-1520.
Akio Nagasaka
Department of Internal Medicine
Fujita Health University
School of Medicine
Toyoake, Aichi, 470-11
Japan 


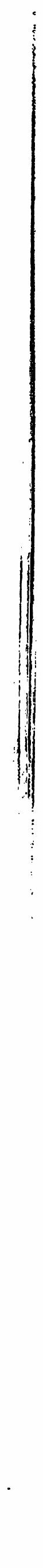

